\title{
NONLINEAR PROPERTIES OF BARIUM TITANATE CERAMICS
}

\author{
IVAYLO LAZAROV ${ }^{1 *}$, ANKA ZHEGLOVA ${ }^{1}$ \\ ${ }^{I}$ Technical University of Gabrovo, Hadzi Dimitar 4, Gabrovo, 5300, Bulgaria
}

\begin{abstract}
The materials based on barium titanate have nonlinear dependence of polarization on the intensity of the electrical field. The properties of those materials are used when different automation elements such as primary converters, phase regulators for low and high frequencies, sensors, modulators etc. are derived. Ceramics based on barium titanate $\left(\mathrm{BaTiO}_{3}\right)$ alloyed with $\mathrm{H}_{3} \mathrm{BO}_{3}$ and $\mathrm{Bi}_{2} \mathrm{O}_{3}$ have been derived and researched. The influence of the temperature of sintering on the values of the dielectric permittivity on the structural properties has been determined. The influence of the quantity of the added material on the temperature dependencies and the non-linear properties of the ceramics have been analyzed. Both legation additives decrease the sintering temperature. However, the values of the dielectric permittivity decrease while the non-linear properties of the doped barium titanate $\left(\mathrm{BaTiO}_{3}\right)$ improve. The coefficient of non-linearity reaches its maximum for the $\mathrm{H}_{3} \mathrm{BO}_{3}$ composites, synthesized at temperature of $1100{ }^{\circ} \mathrm{C}$.
\end{abstract}

Keywords: barium titanate, non-linear properties, doped additives

\section{INTRODUCTION}

Advances in modern automation systems require a search for new functional materials, including nonlinear dielectrics whose properties are influenced by an external electric field. Those materials have found application in dynamic RAM, tuneable microwave devices, such as tuneable oscillators, phase shifters, reactors with a large tuneable capacitance range and low dielectric loss, transducers and sensors [1-3], thermistors [4], and multilayer ceramic capacitors [5].

Barium titanate $\left(\mathrm{BaTiO}_{3}\right)$ is a perovskite-type ceramics material, exhibiting very good properties like low dielectric losses, high values of the dielectric permittivity and high electromechanical coupling coefficients [1].

Lead-free piezoelectric barium titanate and its solid composites are in high demand due to the requirement to find a replacement for lead zirconate titanate (PZT) ceramics. These ceramic materials have high volatility and toxicity, which contaminate the environment [3].

The electrical properties of ferroelectric materials can be modified by doping in or- der to meet the requirements for some applications. The dopants (additions) like $\mathrm{NiO}, \mathrm{ZrO}$ and $\mathrm{Nb}_{2} \mathrm{O}_{5}$ influence the grain size and phase transition temperature of the Barium titanate (BaTiO3) ceramics [6-8]. The dielectric properties of these materials depend very much on grain size.

Ceramic materials of $\mathrm{Ba}_{0 .} \mathrm{Li}_{0.1} \mathrm{Ni}_{0.05}$ by conventional state reaction were prepared. The high value for dielectric permittivity and low dielectric loss were obtained [9].

\footnotetext{
* Corresponding author, email: iv.lazarov@mail.bg

(c) 2016 Alma Mater Publishing House
} 
The addition of cadmium to barium zirconium titanate reduces dielectric losses and increase value of piezoelectric charge constant $\mathrm{d}_{33}[10]$. The legation additives used are $\mathrm{Bi}_{2} \mathrm{O}_{3}$ and $\mathrm{H}_{3} \mathrm{BO}_{3}$, which have relatively low melting temperature. They allow liquid phase synthesis of the ceramic materials and can stimulate the solidstate reactions. The density, the dielectric permittivity and the dielectric losses strongly depend of the sintered temperature.

\section{EXPERIMENTAL DETAILS}

The following composites have been derived in order to analyze the influence of bismuth trioxide $\mathrm{Bi}_{2} \mathrm{O}_{3}$ and boric acid $\mathrm{H}_{3} \mathrm{BO}_{3}$ on the non-linear properties of barium titanate $\left(\mathrm{BaTiO}_{3}\right)$, Table 1.

Table 1. Study composition.

\begin{tabular}{|c|c|}
\hline № & Composite \\
\hline 1. & $\mathrm{BaTiO}_{3}+1 \mathrm{~mol} \% \mathrm{H}_{3} \mathrm{BO}_{3}$ \\
\hline 2. & $\mathrm{BaTiO}_{3}+2 \mathrm{~mol} \% \mathrm{H}_{3} \mathrm{BO}_{3}$ \\
\hline 3. & $\mathrm{BaTiO}_{3}+3 \mathrm{~mol} \% \mathrm{H}_{3} \mathrm{BO}_{3}$ \\
\hline 4. & $\mathrm{BaTiO}_{3}+4 \mathrm{~mol}_{2} \mathrm{H}_{3} \mathrm{BO}_{3}$ \\
\hline 5. & $\mathrm{BaTiO}_{3}+0.05 \mathrm{~mol} \% \mathrm{Bi}_{2} \mathrm{O}_{3}$ \\
\hline
\end{tabular}

The samples of ceramic materials were prepared by conventional mixed oxide solid state reaction method. The raw materials of extra pure grade $\mathrm{BaCO}_{3}, \mathrm{TiO}_{2}, \mathrm{H}_{3} \mathrm{BO}_{3}$ and $\mathrm{Bi}_{2} \mathrm{O}_{3}$ were weighed in appropriate proportion to obtain the stoichiometric ratio. The barium carbonate $\mathrm{BaCO}_{3}$ and titanium dioxide $\mathrm{TiO}_{2}$ are mixed with distilled water in zirconia vials, using zirconia ball, by Reach PM-100 planetary mill. Homogenization was done for duration of 4 hours. Homogenized mixtures dried at a temperature of $150^{\circ} \mathrm{C}$ after removing the zirconia ball. Prepared powder was pressed into pellets of $50 \mathrm{~mm}$ diameter and 20-25 mm thickness. As a binder have been using 3\% water solution polyvinyl alcohol. The pellets of the made materials are sintered at a temperature of $900^{\circ} \mathrm{C}$ for 3 hours. After that, the pellets were crushed using planetary ball mill, after adding the necessary amounts of $\mathrm{H}_{3} \mathrm{BO}_{3}$ or $\mathrm{Bi}_{2} \mathrm{O}_{3}$. Milling powder was pressed into pellets of $10 \mathrm{~mm}$ diameter and 1.5-2 mm thickness and was calcined at a different temperature for 3 hours.

\section{RESULTS AND DISCUSSION}

An X-Ray Diffractometer with a monochromatic $\mathrm{Cu}-\mathrm{K} \alpha$ radiation was used to ex-amine the crystal structure of the sintering ceramic materials over a $2 \theta$ angle from $20^{\circ}$ to $80^{\circ}$.

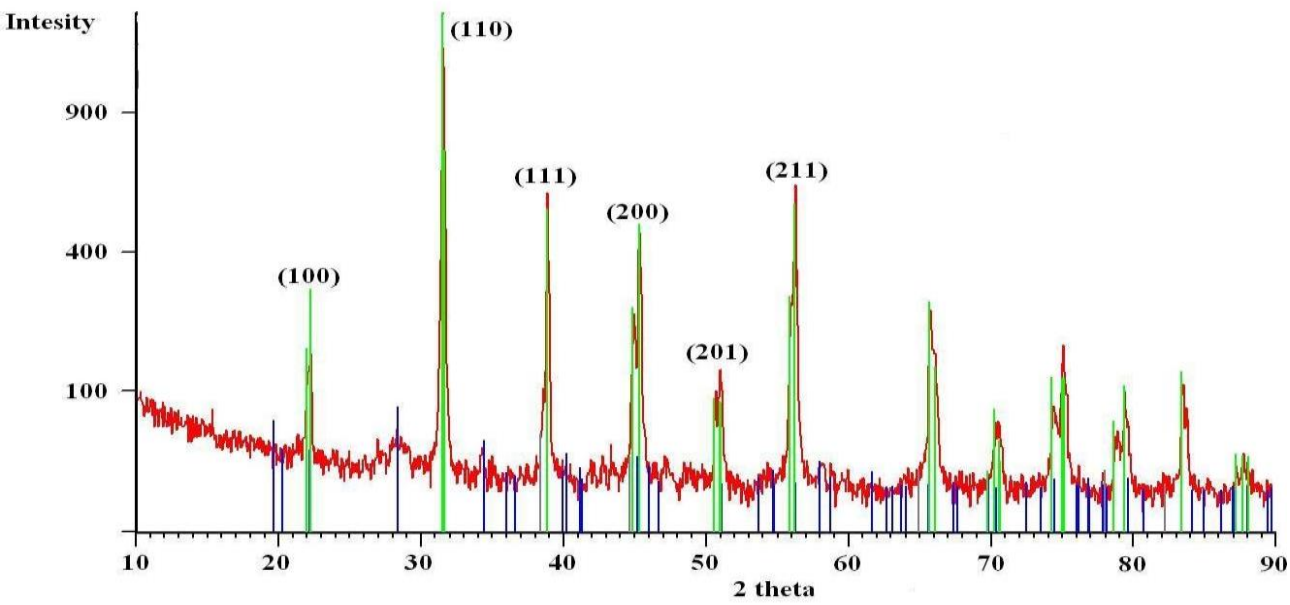

Fig. 1. X-ray diffractogram of $\mathrm{BaTiO}_{3}$ doped with $2 \mathrm{~mol} \% \mathrm{H}_{3} \mathrm{BO}_{3}$ synthesized at temperature $1100^{\circ} \mathrm{C}$. 
Figure 1 shows the diffractogram of $\mathrm{BaTiO}_{3}$, containing $2 \%$ of $\mathrm{H}_{3} \mathrm{BO}_{3}$, the synthesized at temperature $1100^{\circ} \mathrm{C}$. From the diffractograms can be seen that the researching composition have single phase perovskite structure. Similar results were derived for the samples of the other analyzed composites, synthesized at different temperatures.

The Scanning Electron Microscope (SEM) was used for researching the microstructures of the surfaces. The average grain size of the specimen, doped with $2 \mathrm{~mol} \% \mathrm{H}_{3} \mathrm{BO}_{3}$, was about $1-2 \mu \mathrm{m}$ and there was no dependences on the variation of the sintering temperature (Figure 2).

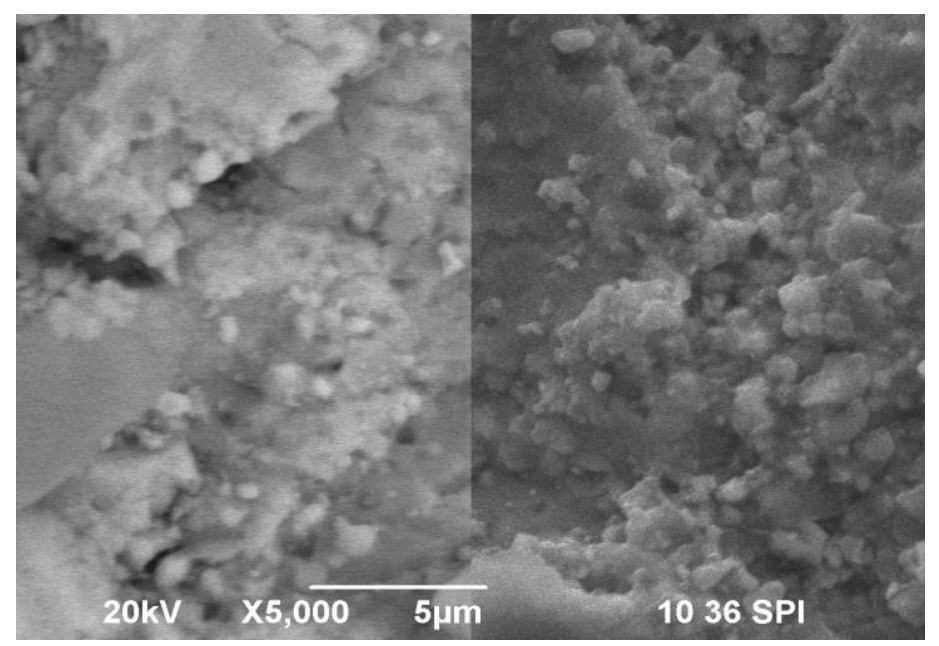

Fig. 2. a) and b) SEM of composite $\mathrm{BaTiO}_{3}+2 \mathrm{~mol} \% \mathrm{H}_{3} \mathrm{BO}_{3}$, synthesized at temperature of $1250^{\circ} \mathrm{C}$.

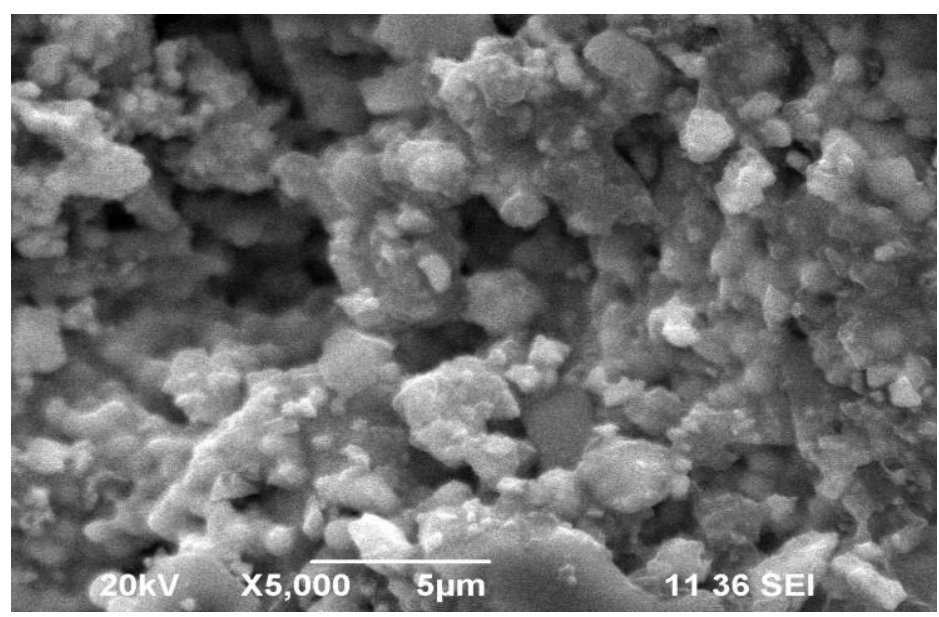

Fig. 3. SEM of composite $\mathrm{BaTiO}_{3}+3 \mathrm{~mol} \% \mathrm{H}_{3} \mathrm{BO}_{3}$, synthesized at temperature of $1250^{\circ} \mathrm{C}$.

The temperature dependencies of the dielectric permittivity have been analyzed. For those dependencies for a composite containing $2 \mathrm{~mol} \% \mathrm{H}_{3} \mathrm{BO}_{3}$, synthesized at different temperatures, phase transitions at Curie point have been observed. The phase transition is most evident at the highest sintering temperature. The higher quantity of the boric acid leads to decrease the values of the dielectric permittivity and to diffuse phase transition. For the materials sintered at low temperatures have been obtained diffuse phase transition. Table 2 shows the composites containing $\mathrm{H}_{3} \mathrm{BO}_{3}$, their dielectric permittivity and the Curie point for samples synthesized at different temperatures.

The temperature dependencies of the dielectric permittivity for compositions of doped barium titanate with 2 mol $\% \mathrm{H}_{3} \mathrm{BO}_{3}$ and $0.05 \mathrm{~mol} \% \mathrm{Bi}_{2} \mathrm{O}_{3}$ are showed in the Figure 4 and the Figure 5. The addition of $0.05 \mathrm{~mol}^{2} \mathrm{Bi}_{2} \mathrm{O}_{3}$ 
to the barium titanate $\left(\mathrm{BaTiO}_{3}\right)$ significantly reduces the dielectric permittivity of the materials and leads to a diffuse phase transition.

Table 2. Dielectric permittivity and Curie temperature at a different sintering temperature.

\begin{tabular}{|c|c|c|c|}
\hline Composite & $\mathrm{t}_{\text {sintering }}\left({ }^{\circ} \mathrm{C}\right)$ & $\varepsilon_{\mathrm{r}}$ & Curie Point $\left({ }^{\circ} \mathrm{C}\right)$ \\
\hline \multirow{5}{*}{$\mathrm{BaTiO}_{3}+1 \mathrm{~mol}^{2} \mathrm{H}_{3} \mathrm{BO}_{3}$} & 1050 & 467 & 33 \\
\hline & 1100 & 487 & 112 \\
\hline & 1150 & 169 & 112 \\
\hline & 1200 & 3627 & 111 \\
\hline & 1250 & 3729 & 112 \\
\hline \multirow{5}{*}{$\mathrm{BaTiO}_{3}+2 \mathrm{~mol}^{2} \mathrm{H}_{3} \mathrm{BO}_{3}$} & 1050 & 916 & 104 \\
\hline & 1100 & 836 & 106 \\
\hline & 1150 & 1589 & 109 \\
\hline & 1200 & 1427 & 107 \\
\hline & 1250 & 2678 & 106 \\
\hline \multirow{5}{*}{$\mathrm{BaTiO}_{3}+3 \mathrm{~mol}_{2} \mathrm{H}_{3} \mathrm{BO}_{3}$} & 1050 & 384 & 110 \\
\hline & 1100 & 192 & 120 \\
\hline & 1150 & 510 & 120 \\
\hline & 1200 & 1279 & 117 \\
\hline & 1250 & 748 & 116 \\
\hline \multirow{5}{*}{$\mathrm{BaTiO}_{3}+4 \mathrm{~mol}_{2} \mathrm{H}_{3} \mathrm{BO}_{3}$} & 1050 & 468 & 107 \\
\hline & 1100 & 562 & 105 \\
\hline & 1150 & 385 & 115 \\
\hline & 1200 & 965 & 114 \\
\hline & 1250 & 927 & 113 \\
\hline \multirow{5}{*}{$\mathrm{BaTiO}_{3}+0.05 \mathrm{~mol} \% \mathrm{Bi}_{2} \mathrm{O}_{3}$} & 1050 & 972 & 103 \\
\hline & 1100 & 958 & 120 \\
\hline & 1150 & 420 & 117 \\
\hline & 1200 & 1179 & 96 \\
\hline & 1250 & 841 & 114 \\
\hline
\end{tabular}

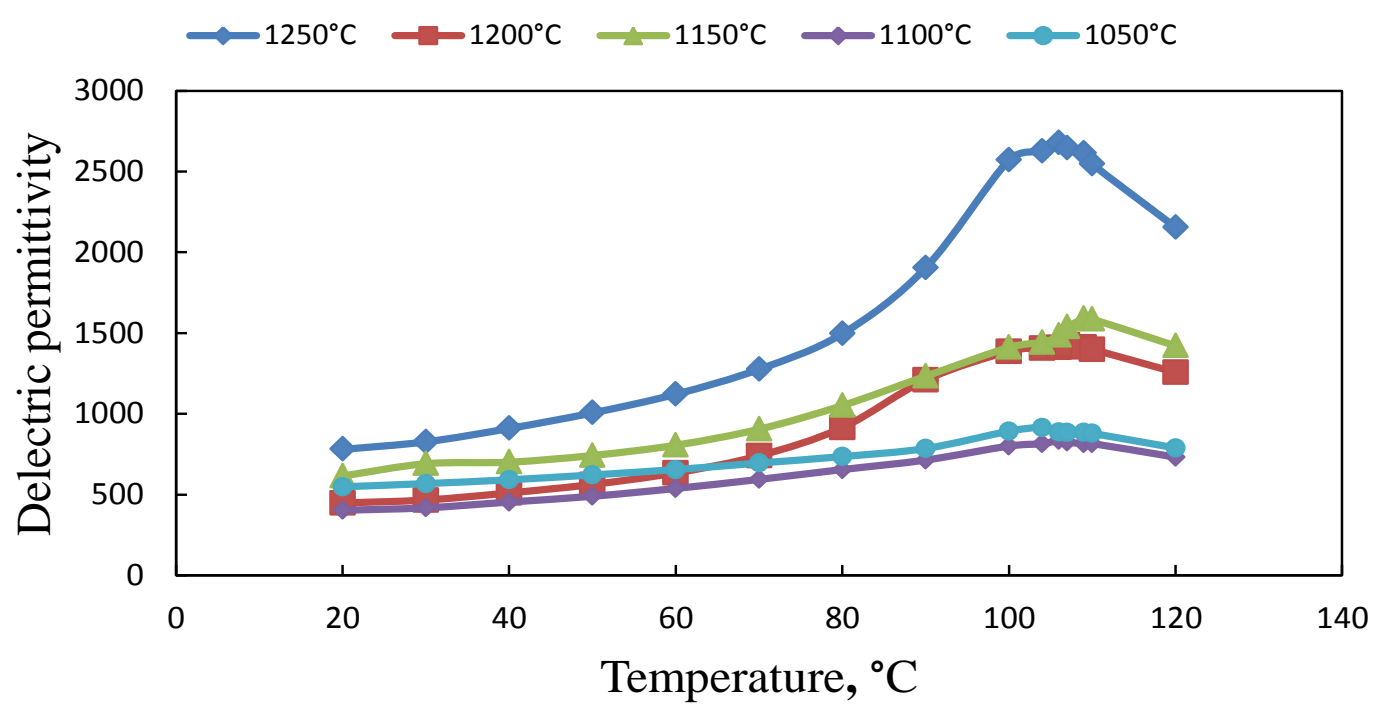

Fig. 4. Temperature dependencies of the dielectric permittivity for a composite containing $2 \mathrm{~mol}^{2} \mathrm{H}_{3} \mathrm{BO}_{3}$. 


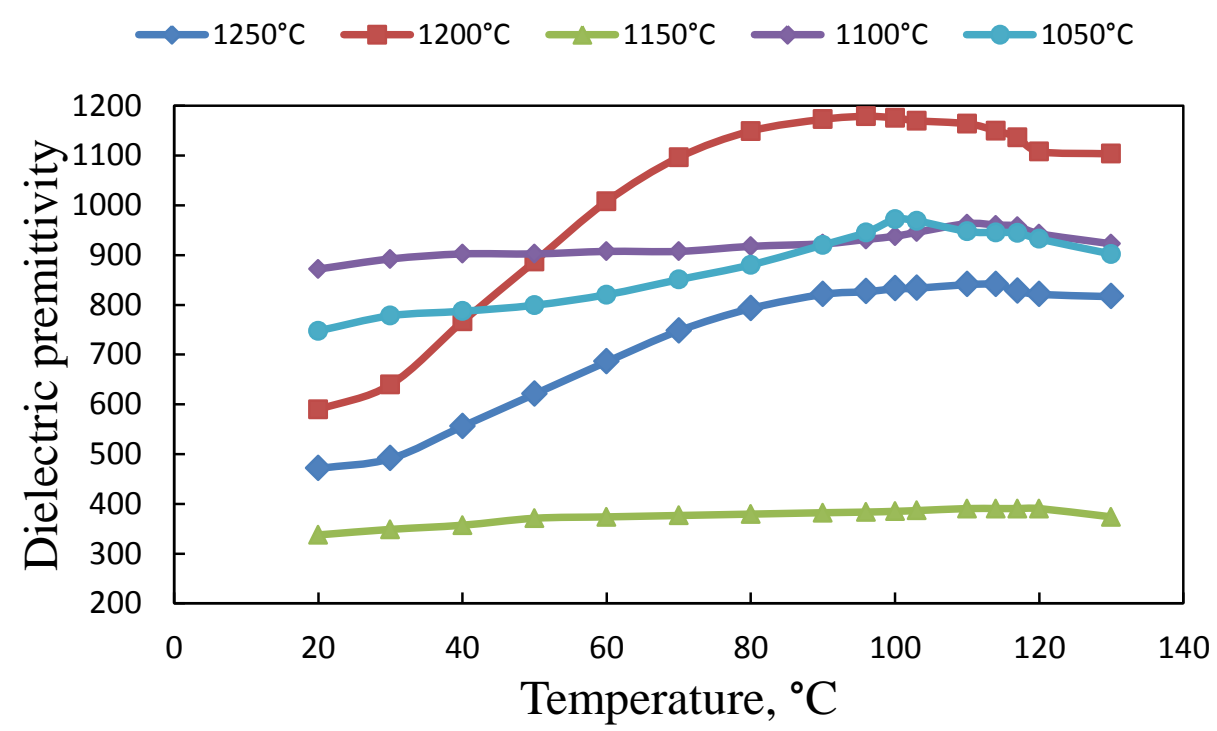

Fig. 5. Temperature dependencies of the dielectric permittivity for a composite containing $0.05 \mathrm{~mol} \% \mathrm{Bi}_{2} \mathrm{O}_{3}$.

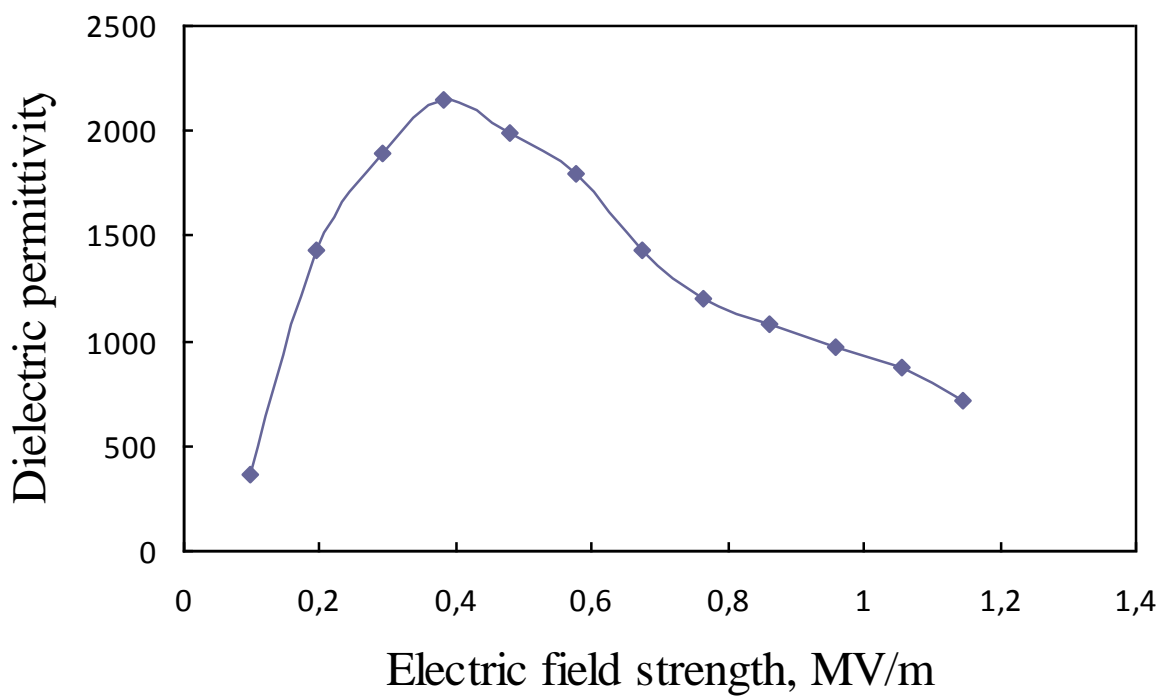

Fig. 6. Dependency of the dielectric permittivity on the electric field strength for materials $\mathrm{BaTiO}_{3}$ $+1 \mathrm{~mol} \% \mathrm{H}_{3} \mathrm{BO}_{3}$, sintered at temperature $1100^{\circ} \mathrm{C}$.

For evaluation of the nonlinear properties of the ferroelectrics, a non-linearity coefficient $\mathrm{K}$ is defined, which shows how many times the dielectric permittivity increases when the electric field strength increases compared to its initial value [11].

$$
K=\frac{\varepsilon_{r \max }}{\varepsilon_{r_{\text {initial }}}}
$$

Figure 6 and Figure 7 present the dependencies of the dielectric permittivity on the electric field strength for the materials which have been obtained good non-linear properties. 


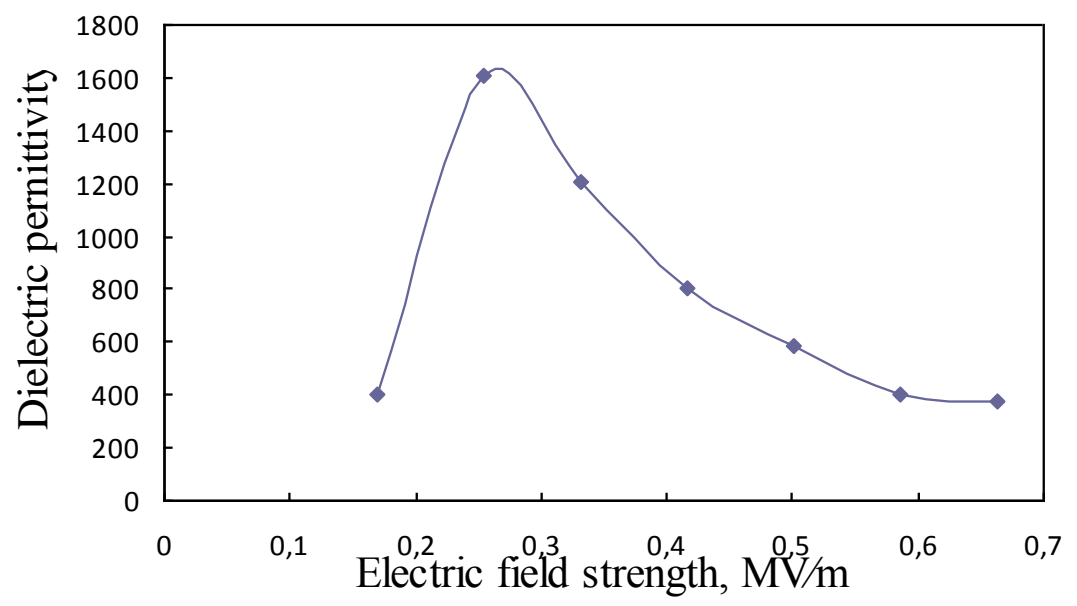

Fig. 7. Dependency of the dielectric permittivity on the electric field strength for materials $\mathrm{BaTiO}_{3}+3 \mathrm{~mol}_{\%} \mathrm{H}_{3} \mathrm{BO}_{3}$, sintered at temperature $1100^{\circ} \mathrm{C}$.

For the non-linear ceramics, an important parameter is maximum values of the dielectric permittivity on the electric field strength. The values of the electric field for the analyzed materials, at which the dielectric permittivity reaches its maximum, are presented in Table 3. Table 3 shows a comparison of the non-linear properties of the ceramic materials, containing $\mathrm{BaTiO}_{3}$ at different sintering temperatures.

Table 3. Comparison of the non-linear properties of the ceramic materials, containing $\mathrm{BaTiO}_{3}$ at different sintering temperatures.

\begin{tabular}{|c|c|c|c|c|}
\hline Composite & $\mathrm{t}_{\text {sintering }}\left({ }^{\circ} \mathrm{C}\right)$ & $\varepsilon_{\text {rinitial }}$ & $\varepsilon_{\mathrm{rmax}}$ & $\mathrm{K}$ \\
\hline $\mathrm{BaTiO}_{3}+1 \mathrm{~mol}^{2} \mathrm{H}_{3} \mathrm{BO}_{3}$ & $1050^{\circ} \mathrm{C}$ & 2066,0 & 3305,6 & 1.6 \\
\hline $\mathrm{BaTiO}_{3}+1 \mathrm{~mol} \% \mathrm{H}_{3} \mathrm{BO}_{3}$ & $1100^{\circ} \mathrm{C}$ & 358,5 & 2151,1 & 6,0 \\
\hline $\mathrm{BaTiO}_{3}+1 \mathrm{~mol} \% \mathrm{H}_{3} \mathrm{BO}_{3}$ & $1150^{\circ} \mathrm{C}$ & 594,6 & 1486,6 & 2.5 \\
\hline $\mathrm{BaTiO}_{3}+2 \mathrm{~mol}_{\%} \mathrm{H}_{3} \mathrm{BO}_{3}$ & $1050^{\circ} \mathrm{C}$ & 1534,0 & 2679 & 1,7 \\
\hline $\mathrm{BaTiO}_{3}+2 \mathrm{~mol} \% \mathrm{H}_{3} \mathrm{BO}_{3}$ & $1100^{\circ} \mathrm{C}$ & 593,1 & 2668,6 & 4,5 \\
\hline $\mathrm{BaTiO}_{3}+3 \mathrm{~mol} \% \mathrm{H}_{3} \mathrm{BO}_{3}$ & $1100^{\circ} \mathrm{C}$ & 235,9 & 1603,5 & 6,8 \\
\hline $\mathrm{BaTiO}_{3}+3 \mathrm{~mol}^{2} \mathrm{H}_{3} \mathrm{BO}_{3}$ & $1150^{\circ} \mathrm{C}$ & 423,9 & 1341,7 & 3,2 \\
\hline $\mathrm{BaTiO} 3+0,05 \mathrm{~mol} \% \mathrm{Bi}_{2} \mathrm{O} 3$ & $1050^{\circ} \mathrm{C}$ & 524 & 1563,0 & 3,1 \\
\hline $\mathrm{BaTiO} 3+0,05 \mathrm{~mol} \% \mathrm{Bi}_{2} \mathrm{O}_{3}$ & $1150^{\circ} \mathrm{C}$ & 557 & 1115,9 & 2,1 \\
\hline
\end{tabular}

The addition of $\mathrm{H}_{3} \mathrm{BO}_{3}$ to ceramic materials containing barium titanate leads to higher values of the non-linear coefficient compared to the addition of $\mathrm{Bi}_{2} \mathrm{O}_{3}$ to the same materials. The optimal sintering temperature for the first group of materials is $1100^{\circ} \mathrm{C}$, whereas for the materials doped with $\mathrm{Bi}_{2} \mathrm{O}_{3}$ that temperature is $1050^{\circ} \mathrm{C}$. Both of those additions significantly increase the non-linear properties of the barium titanate $\left(\mathrm{BaTiO}_{3}\right)$, but decrease the values of the dielectric permittivity. That increase is higher when was added $\mathrm{Bi}_{2} \mathrm{O}_{3}$.

The sintering temperature decreases by $200-250^{\circ} \mathrm{C}$ when $\mathrm{H}_{3} \mathrm{BO}_{3}$ и $\mathrm{Bi}_{2} \mathrm{O}_{3}$ are added to the barium titanate $\left(\mathrm{BaTiO}_{3}\right)$. That temperature is $1350{ }^{\circ} \mathrm{C}$ for pure barium titanate $\left(\mathrm{BaTiO}_{3}\right)$. Simultaneously, the non-linear properties improve while the dielectric permittivity decreases.

\section{CONCLUSIONS}

Ceramic materials based on Barium titanate with 1,2,3 and $4 \mathrm{~mol} \% \mathrm{H}_{3} \mathrm{BO}_{3}$ as well as $\mathrm{BaTiO}_{3}$ with $0.05 \mathrm{~mol} \%$ $\mathrm{Bi}_{2} \mathrm{O}_{3}$, have been synthesized at temperatures $1050,1100,1150,1200$ and $1250^{\circ} \mathrm{C}$. The diffractograms show the synthesis of mono phase structure with reflexes typical for the barium titanate. According to SEM the structure of the materials is relatively homogeneous and the size of the beans is up to $10 \mu \mathrm{m}$. 
For materials derived from $\mathrm{BaTiO}_{3}$ doped with $1 \mathrm{~mol} \%$ and $2 \mathrm{~mol} \% \mathrm{H}_{3} \mathrm{BO}_{3}$ have been obtained high values of the relative permittivity sintered at higher temperatures. For these materials the phase transition are obvious.

For materials derived from $\mathrm{BaTiO}_{3}$ doped with $0.05 \mathrm{~mol} \% \mathrm{Bi}_{2} \mathrm{O}_{3}$ have been obtained the diffuse phase transitions at all temperature of sintered.

The most suitable materials for non-linear elements are the ceramics based on $\mathrm{BaTiO}_{3}$, doped with $\mathrm{H}_{3} \mathrm{BO}_{3}$ and sintered at temperature $1100^{\circ} \mathrm{C}$.

\section{REFERENCES}

[1] Noh, H.J., Lee, S.G., Yoon, S.E., Park, S.M., Dielectric properties of $\mathrm{Yb}_{2} \mathrm{O}_{3}-$ doped barium strontium titanate thick films for microwave device applications, Journal Material Science, vol. 43, 2008, p. 3421-3416.

[2] Kamehara, N., Karihara, K., Effect of rare earth elements doping on the electrical properties of $(\mathrm{Ba}, \mathrm{Sr}) \mathrm{TiO}_{3}$ thim film capacitor, VLSI Packaging Workshop of Japan, 2008, p. 113-116.

[3] Mahesh, M., Bhanu Prasad, V., James, A., Effect of sintering temperature on the microstructure and electrical properties of zirconium doped barium titanate ceramics, Journal Material Science: Material Electronics, vol. 24, 2013, p. $4684-4692$.

[4] Liu, J., Gong, S., Jin, G., Zhai, Z., Zhao, Z., Luo, C., Jiang, Q., Influence of reoxidation on silica-containing barium titanate ceramics for PTRC thermistors prepared by tape casting, Journal Ceramics - Silicáty, vol.60, no.2, 2016, p. 58-62.

[5] Jain, A., Maikhuri, N., Rakesh, S., Pastor, M., Jha, A.K., Panwar, A.K., Microstructural and dielectric investigations of vanadium substituted barium titanate ceramics, Advanced Material Letters, vol. 7,no. 7, 2016, p. 567-572.

[6] Li, L., Fu, R., Liao, Q., Ji, J., Doping behaviors of $\mathrm{NiO}$ and $\mathrm{Nb}_{2} \mathrm{O}_{5}$ in $\mathrm{BaTiO}_{3}$ and dielectric properties of $\mathrm{BaTiO}_{3}$ - based X7R ceramics, Journal Ceramics International, vol.38, 2012, p. 1915-1920.

[7] Armstrong, T., Morgens, E., Maurice, A., Buchanan, R., Effects of zirconia on microstructure and dielectric properties of barium titanate ceramics, Journal American Ceramics Society, vol.72, no.4, 1989, p. 605-61.

[8] Lu, Y., Hao, H., Zhang, S., Liu, H., Su, C., Yao, Z., Cao, M., Microstructure and dielectric characteristics of $\mathrm{Nb}_{2} \mathrm{O}_{5}$ - doped $\mathrm{BaTiO}_{3}-\left(\mathrm{Bi}_{1 / 2} \mathrm{Ti}_{1 / 2}\right) \mathrm{O}_{3}$ ceramics for capacitor applications, Journal of the European Ceramics Society, vol. 37, 2017, p. 123-128.

[9] Alkathy, M., Gayam, R., Hazra, B.K., Raju, K.C., Effect of sintering on structural and physical properties of nickel and lithium co-substituted barium titanate ceramics, Journal Ceramics International vol. 43, 2017 , p. 4937-4949.

[10] Bajpaj, K.K., Srenivas, K., James, O.P., James, A,R., Shukla, A.K, Influence of Cd on the electro-strain of barium zirconate ceramics, Journal Ceramics International, vol. 43, 2017, p. 1963-1967.

[11] Verbitkaya, T., Varicond, 1st edn. Gosenergoizdat, Moscow,1958, p. 62 (In Russian). 